\title{
Performing Together: Monozygotic Twin Comedians/Twin Research: Mirror-Image Cleft Lip and Palate; Dental Caries; Noninvasive Prenatal Testing; Capgras Syndrome With Folie à Deux/In the News: Athletic Twins; Transgendered Twins; Crib-Sharing; Common Careers
}

\author{
Nancy L. Segal \\ Department of Psychology, California State University, Fullerton, CA, USA
}

\begin{abstract}
Twin studies have shown that our sense of humor has an underlying genetic component, but less investigation of the origins of stand-up comedy has been undertaken. This article briefly reviews twin research findings on humor, then describes the working partnership and social affiliation of a pair of monozygotic male twins who perform together as stand-up comedians. The abilities, personalities and temperaments of these twins suggest future avenues for research in this interesting area. Next, findings from twin studies and case reports of twins with cleft lip and palate, dental caries, noninvasive prenatal testing and Capgras syndrome (with folie à deux) are summarized. In conclusion, recent news about athletic twins, transgendered twins, crib-sharing and career choice are presented.
\end{abstract}

\section{Performing Together}

\section{Monozygotic Twin Comedians}

The origins of our sense of humor - in particular, individual differences in what people find funny and how they convey that sense to others - have been topics of great interest among behavioral science researchers. Twin studies have demonstrated meaningful genetic components to variation in the many aspects of humor. Among them are humor styles and loneliness (Schermer et al., 2017), and laughter and resiliency (Veselka et al., 2010). Other aspects of humor have also been of examined, namely health (Greengross \& Martin, 2018) and personality (Greengross et al., 2012a).

In contrast with the above, relatively less attention has been given to factors underlying stand-up comedy. Perhaps, this lack of attention reflects the relative rarity of monozygotic (MZ) twins who are both stand-up comics and work together as such. Fortunately, two studies in this area are available and offer unique insights into this intriguing profession. Greengross and Miller (2009) found that professional stand-up comedians were similar to amateur stand-up comedians in personality, but that both groups showed higher scores on openness and lower scores on conscientiousness, extraversion and agreeableness than college students. Comedy writers showed higher openness, conscientiousness, extroversion and agreeableness than stand-up comedians. It was suggested that comedians are not the neurotic extroverts that many people believe them to be. Greengross et al. (2012b) also

\section{Author for correspondence: Nancy L. Segal, Email: nsegal@fullerton.edu}

Cite this article: Segal NL. (2019) Performing Together: Monozygotic Twin Comedians/Twin Research: Mirror-Image Cleft Lip and Palate; Dental Caries; Noninvasive Prenatal Testing; Capgras Syndrome With Folie à Deux/In the News: Athletic Twins; Transgendered Twins; Crib-Sharing; Common Careers. Twin Research and Human Genetics 22: 70-74, https://doi.org/10.1017/thg.2018.74 challenged the view that stand-up comedians have different childhood experiences than their peers and differ from other adolescents in popularity.

I was fortunate to have met Adam and Todd Stone (of the comedy show Stone and Stone) in 2013 when we were invited to participate in an unscripted round-table discussion, 'Are Humor and Other Traits Genetic? Identical Twins Reared Apart,' at the comedy cellar in New York City. This session was prompted by the publication of my book, Born together - reared apart: The landmark Minnesota Twin Study (Segal, 2012). I contacted the twins again in 2018, and they agreed to an interview to help researchers understand the ingredients of being a stand-up comedian and how being a twin affects success in this particular occupation.

The Stone twins were born on March 22, 1983, making them 35 years of age at the time of our interview. Adam lives in Montclair, New Jersey with his wife and two children and Todd lives on his own in the heart of the city. I am confident that they are $\mathrm{MZ}$ twins based on the results of their physical resemblance questionnaire (Nichols \& Bilbro, 1966) and the fact that their faces appear exactly alike; a photo of the twins is displayed in Figure 1. However, there are a few obvious physical differences, namely that Adam is right-handed while Todd is ambidextrous, and Todd is about 1 inch shorter and 20 pounds lighter than Adam. Interestingly, Todd has a somewhat smaller appetite than his twin, who has to watch his weight more diligently. I have known other twins whose weight difference may be linked to their desire for food, although the source of this difference is unclear.

I argue strongly against twin classification based on appearance or twins' self-report, as indicated in the research review below (see the section on twin studies of dental caries). However, Race and Sanger (1975), in a reference to the late twin researcher James 


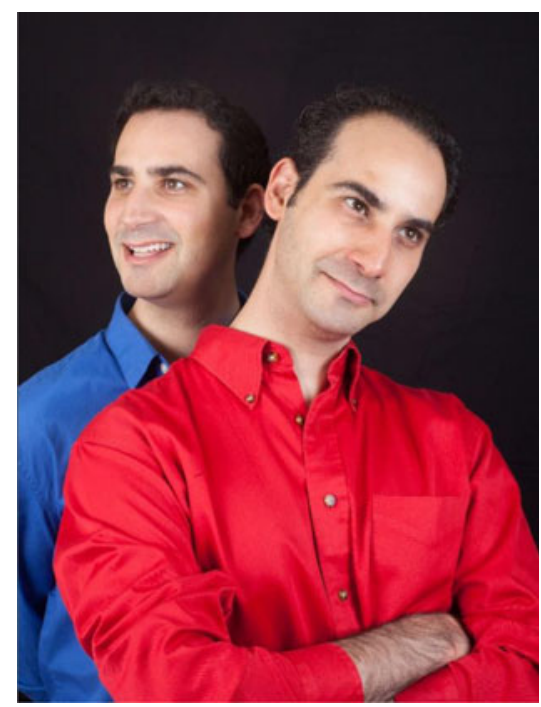

Fig. 1. Identical twins and stand-up comedians, Adam (left) and Todd Stone. Photo credit: Morgan Shortell.

Shields, noted that 'We find that the blood groups practically never contradict the opinion of such a skilled observer of twins.' If the Stone twins' physical resemblance questionnaire results were unavailable, I would judge them to be identical, based on their matched appearance, but would be hesitant to write about them in a scientific context without further evidence - for example, a DNA test.

Being an identical twin is very important to both Adam and Todd. Todd has always believed that he and his brother are part of an identical pair, but claims that belief can be stronger than reality: 'Even if we are not identical, we are identical.' Adam suspects that there is a kind of hierarchy among twins, ranging from identical to same-sex fraternal to opposite-sex. 'But whether or not you are identical technically, if you look alike, think alike and act alike then you have the twin experience.' When I first met the twins in 2013, they were very relieved to learn that my global impression of them was that they are indeed identical twins.

Adam is a comedian. He also writes comedy at 'truTV' by day and performs stand-up comedy by night. Todd, also a comedian, writes for a small trade publication, but joins his twin as a performer in the evening. Perhaps their talent emerged in middle school and high school where they were involved in theatrical productions, and Todd also sang songs, mostly American standards. After graduating from high school, they attended college together at Wesleyan University in Middletown, Connecticut. Their application process is important to understand as it underlines salient features of their relationships as twins and co-comedians.

Adam and Todd have always been very close as brothers, so they felt that it was crucial for them to attend college together. Both twins applied for early admission to Wesleyan. Because early admission means that students who are accepted are obligated to attend, they both indicated in their personal statements that if one twin was accepted, the other should be accepted - and that if one twin was rejected, the other should be rejected. Fortunately, both twins were accepted, and as freshman decided to experiment with separation; they asked to be assigned to the same dormitory just down the hall from one another. The following year they became each other's roommates, an arrangement that lasted from their sophomore through senior years. After graduating from college, they lived at home for 2 years, then roomed together in New York City for 5 years until Adam moved in with his now wife. Todd jokes that 'Adam left him!'

Note that the decision-making processes and strategies that twins use when applying to college have not been well studied, nor have their outcomes. Twins contemplating going to college together might consider applying the Stone twins' approach.

Adam and Todd's lives as comedians began during their college years. Adam had hoped to continue with theater arts in college, but opportunities were limited. Reasoning that stand-up comedy was also considered a performance art, he decided to try it. He joined a stand-up comedy group, took it seriously, wrote jokes and did very well. Todd attended several shows and was delighted by his twin's success, leading them to decide to put on a show together on campus; Todd reasoned that if his twin was funny than he could be as well. They called their joint show Stone and Stone. In their first show, Todd sang Elvis Presley songs and Adam did standup, bringing Todd into the routine at the right moments, but Todd also delivered humorous lines. The twins performed their Stone and Stone shows several times a year, and for their final senior year show they drew an audience of nearly 500 people. At that point, upon graduation, they moved back home to a suburb of New York City and entered the comedy circuit there.

Adam and Todd work together well as brothers and as co-comedians, but have different personas - Adam is louder with bigger gestures and Todd is quieter and slightly more serious. The brothers keep the various parts of their production and performing 'equal and fair.' Their working formula is simple and effective: One twin comes up with something humorous, writes it down and pitches it to his brother - if he thinks it is funny, then they try it out on stage. (A unique quality of stand-up comedy is that these entertainers both create and perform their own work; Greengross \& Miller, 2009). Todd boasts that he has an automatic writing partner, something for which he is very grateful, but writing is a 'team effort.' Todd calls Adam a driving force that moves the two of them forward, as they feed ideas to each other in order to enhance a concept or a joke. Todd works well with the other people at his day job, but admits that working with Adam is 'different.' They share a level of honesty that goes beyond what they share with others.

Sometimes there are sensitivities, such as when one twin enjoys a more receptive audience on a given evening. When this imbalance happens, they have a correction formula that is also straightforward and simple - the less successful twin tries to improve or change the routine to return to the same level as his brother. There is no lingering animosity.

I wondered if these twins ever perform as individuals, and what it would be like for them to work with other people on stage. Adam said it is possible to perform alone, but it is something they do very rarely, and mostly if one twin has to cancel for some reason. Several months ago when Todd was away, Adam did his own set that lasted about 8 minutes. Interestingly, he played off the fact that he normally performs with Todd because he looked over to an imaginary person, and his set went very well. At the same time, it was reassuring for Adam to know that the twin element is not what makes him a comedian. Nevertheless, twinship means a great deal for both brothers.

The Stones are thinking about doing a show with a set of their twin friends, the jazz musicians Peter and Will Anderson, whom I wrote about in an earlier issue of Twin Research and Human Genetics (Segal, 2018). They also find that watching the routines of the comedians whose acts precede and follow theirs has shown 
them they that laugh at the same jokes, no doubt explaining why they work well together.

For Adam, twinship is as an amazing experience and a beautiful bond, explaining why his twin brother Todd is his soulmate. He appreciates the uniqueness of their relationship, knowing that many other people wish they had a twin. True to his comedic nature, he also jokes that the two are basically married to one another; in fact, he senses that he married to two people, his wife and his twin. But marriage is a key experience that differentiates him from his brother, giving him a new 'routine' to perform, namely a balancing act between the time he spends with Todd and the time he spends with his wife and family. Over the years, it was important that the twins like each other's partners, so when Todd met his future sister-in-law, he said that she 'passed the test.' This is a common attitude among many MZ twins I have studied. Todd claims to have never met two other people as closely bonded as he is to Adam, another belief held by other identical pairs.

Stone and Stone can be enjoyed regularly at venues throughout the tri-state area, from Manhattan comedy clubs to Brooklyn bar shows to private events in Westchester County and New Jersey. The twins are also developing a new series called 'Going Both Ways.' This series will convey a new dynamic, namely the concepts of Adam having a wife and family and how that has been a big lifestyle change, and Todd's coming out and exploring that world. They financed the project through a crowdfunding campaign and finished filming at the end of November, 2018. They gave their jazz musician friends, the Anderson twins, a cameo appearance in one of the episodes. The series is currently being edited and should be released in early 2019. I have seen a trailer and it is delightful, entertaining, stylish and, of course, very funny; it is available for viewing at this link: https:/www.indiegogo.com/ projects/going-both-ways-web-series\#/.

Adam and Todd exemplify many findings from twin studies that researchers have been conducting for many years. They have similar interests and talents, a successful working partnership and a close personal relationship, likely (and partial) reflections of their shared genes. Educators, managers and talent scouts who identify and promote the abilities of students, interns and entertainment hopefuls are encouraged to examine what twin research reveals, as well as the professional qualities enabling individual twin pairs to be effective in the workplace. Twin researchers whose interests lie at the crossroads of behavioral genetics and industrial relations may acquire fresh leads for understanding the origins and maintenance of harmonious coworker interactions. Those with interests in personality, social relations and/or live entertainment may wish to further explore factors drawing people to careers that depend on having a sense of humor and the ability to convey that sense to others.

\section{Twin Research}

\section{Mirror-Image Cleft Lip and Palate}

Orofacial clefts are the most common defects of the craniofacial region, formed during embryogenesis. The relative concordance rates for MZ (40-60\%) and dizygotic (DZ, 3-5\%) twin pairs indicate that genetic factors play a role; see Takahashi et al. (2018). These Japanese researchers recently detected mirror-image cleft lip and palate in a pair of 4-year-old MZ male twin children. Twin A showed the structural defect on the right side and Twin B showed the same defect on the left. Neither of their parents nor other relatives had a history of orofacial clefts.
Genomic sequencing using saliva samples was performed in a search for genetic variants that might explain the twins' differences, but none were found. The craniomorphology of the twins was also compared, using lateral cephalograms taken for the planning of orthodontic treatment. Lateral cephalograms establish the projection of various craniofacial features, such as the nasion or point where the top of the nose meets the ridge of the forehead. These data establish the relationship of horizontal facial levels to the skull base (Collins English Dictionary, 2018; Fearon, 2010). Some differences in craniofacial angles were found between the twins.

\section{Dental Caries}

Previous studies of twins raised together and apart have yielded genetic effects on many dental characteristics; for example, cavities, tooth size and teeth restored (see Segal, 2012). Interestingly, a new twin study from Indian investigators suggests that the similar dental caries and oral hygiene status of MZ and DZ twins, aged 6-15 years, reflect their shared home environmental influences (Subramaniam et al., 2018). The sample included 129 twin pairs, $71 \mathrm{MZ}$ and $58 \mathrm{DZ}$. However, a problem with this study that could explain the findings is that the twins' zygosity was established by facial appearance and confirmed by only dermatoglyphic analyses. Justification for this pair of procedures is that it is 'easier, noninvasive and requires little cooperation from the twins' (Subramaniam et al., 2018, p. 20). I would disagree as to the efficacy of these methods, noting that neither is a precise index of twin type, especially in a relatively small sample.

Twin studies have shown increased heritability across a range of traits (e.g., general mental ability) as twins progress from childhood to adolescence, reflecting genetic effects (Wilson, 1983). An increase in genetic effects is also seen for sports participation in twins between 13 and 16 years of age (Stubbe et al., 2005). Consistent with these findings, adoption studies of intelligence show reduced similarity between unrelated siblings as they approach the teenage years, also highlighting the waning of shared environmental home influences and an increase in nonshared experiences (Segal et al., 2007). However, shared environments have also explained the exercise behavior of twins of ages 7 and 12 years (Huppertz et al., 2012). Reasoning from these findings to the dental study cited above suggests that young twins living at home may show just slight twin group differences in some dental traits due to their shared dental routines and treatment; however, accurate zygosity assessment is a mandatory first step in any such twin study.

\section{Noninvasive Prenatal Testing}

Noninvasive prenatal testing (NIPT) is a procedure that analyzes cell-free DNA (cfDNA), both maternal and fetal, in samples of maternal blood. Its purpose is to determine whether a fetus is at risk for chromosomal anomalies, such as trisomy 21, trisomy 13, fragile X syndrome and Turner syndrome (XO). Deleted or duplicated portions of chromosomes can also be detected by this method (National Institutes of Health, 2018). A recent study by Japanese researchers in Nagoya and Tokyo documented the characteristics of multiple birth mothers who underwent NIPT and the outcomes of their fetuses or infants (Takeda et al., 2018).

The 75 mothers pregnant with twins were identified from among 4009 mothers who underwent NIPT between 2013 and 2016. This subsample of mothers was generally older in age than average (mean $=38.44, \mathrm{SD}=2.2$, range $=30-51$ years) and likely to have conceived via assisted reproductive technology. Fifteen twin mothers experienced either vanishing syndrome or fetal death 
prior to 22 weeks' gestation. Among the remaining mothers, NIPT results were positive in two cases: one mother had one twin with trisomy 18 and the other mother had two infants with trisomy 21; however, in the second case, the results did not match the results of amniocentesis and karyotyping, which showed normal 46, XY infants. Various other maternal complications, such as premature membrane rupture and breech presentation, were noted in several cases. With respect to the infants, 115 babies were born, whereas 5 were not delivered. The proportion of congenital anomalies was similar to that of non-NIPT Japanese twin pregnancies (8.0\% vs. $7.4 \%)$.

The authors noted that international guidelines for NIPT are variable and some bodies, such as the American College of Obstetricians and Gynecologists, do not recommend its use. Given the limited availability of data regarding the efficacy of the procedure, additional data would be welcome.

\section{Capgras Syndrome (with Folie à deux)}

Capgras syndrome is a well-known delusional disorder in which affected individuals believe that imposters have replaced familiar people. The individuals who are most impersonated are spouses and siblings. Folie à deux includes several subtypes in which delusions are shared between an inducer and a recipient. An additional variety involves the simultaneous appearance of delusions between genetically predisposed individuals. Danish physicians have recently described two episodes of these two conditions in a set of MZ male twins, at ages 46 and 49 years (Gbyl \& Jorgensen, 2018). In their first episode, the twins' symptoms were apparently triggered by excessive alcohol consumption and a small quantity of cannabis while they traveled together. Twin A became affected first. In the second episode, they became affected at a dinner party after consuming beer and wine, and this time, Twin B was the first to be affected. Once their symptoms subsided, both twins became extremely distrustful of the people around them. They decided to use a private password with each other for reassurance and to know for certain if they were in the real world.

The twins' medical history was unremarkable. Twin A had variously experienced emphysema, pulmonary fibrosis and allergy to pollen, while Twin B showed none of these conditions. Neither twin had experienced a psychological or neurological disorder or had suffered a blow to the head or other trauma. The twins were both married and employed at the same company, whose restructuring was quite stressful for them. The investigators suspected that interactions among the twins' genetic predisposition, work factors and psychological mechanisms eventuated in their episodes. They also noted that alcohol and cannabis use can trigger transient periods of Capgras syndrome with folie à deux.

This fascinating case study is limited by the fact that the twins' zygosity was determined by self-report and their physical resemblance to one another, an issue that was recognized by the authors. It is puzzling that a DNA analysis was not undertaken, given that the authors were affiliated with a university hospital. As indicated above, it is possible to administer a standard physical resemblance questionnaire when DNA testing is not feasible.

\section{In the News}

\section{Athletic Twins}

Frank Bruni (2018), sports writer for the New York Times, authored a remarkable tale of twins, Shaquem and Shaquill Griffin, who play professional football for the Seattle Seahawks. It is not unusual to find athletically gifted twins in the same sport or even on the same team, but the Griffin twins are an exception that has attracted considerable attention and admiration. Shaquem suffered from amniotic band syndrome, a condition in which the strands of the amniotic sac wrap around parts of the fetus during prenatal development. This unfortunate condition caused a severe and painful deformity of his left hand; he even tried to sever his fingers with a kitchen knife at the age of 4 . Eventually, his left hand was surgically removed, but his dream of becoming a football player remained intact. Despite discouragement from childhood coaches, he was not dissuaded and went on to star on his high school's football team.

When it came time for college, Shaquem's twin Shaquill would not accept any school that refused to admit his brother. The two eventually attended the University of Central Florida, where Shaquem became a starting linebacker. Both twins were then drafted for the Seattle Seahawks. The article does not say whether the twins are identical or fraternal, but inspection of photographs suggests that they are identical twins.

\section{Transgendered Twins}

Identical twins Jacklyn and Jennifer Grafe were born in 1995 and raised in a conservative Christian home. Both twins knew at an early age that they identified as males, even before they knew or understood the concept of being transgender. Over the years, they went from identifying as homosexual at age 16 to identifying as transgender at age 18 (Rach, 2018).

Both twins underwent surgical reassignment surgery and by age 23 became Jack and Jace. Both graduated from college with criminal justice degrees, work in law enforcement and are in successful relationships with women. The twins admit that sharing their feelings and going from female to male with someone close to them was a great source of understanding and support.

Transitioning from female to male $(1 / 100,000)$ is less common than transitioning from male to female $(1 / 30,000)$, as found by Michel et al. (2001). Twin studies also show that transgenderism has a genetic component, especially among males. Concordance rates are $33.3 \%$ for individuals born as $\mathrm{MZ}$ males, $22.9 \%$ for individuals born as $\mathrm{MZ}$ females and virtually $0 \%$ for individuals born as either DZ males or DZ females (Diamond, 2013).

\section{Crib-Sharing}

Continuing controversies surround the benefits and drawbacks of co-bedding twins (Hogeven, 2018). Various benefits include comfort to the twins, as well as the saving of space and money for families. In contrast, several drawbacks are worries over sudden infant death syndrome (SIDS) because, as one expert notes, another infant in the crib is like having a toy or extra bedding nearby; both are risk factors that could jeopardize an infant's breathing. Note that difficult breathing and failure to recover are thought to be symptomatic of SIDS deaths (Berk, 2013).

Professional appraisal of co-bedding by the American Academy of Pediatrics (AAP) did not firmly establish its pros and cons. Instead, recommendations are that parents share a room with their twins for approximately 6 months, but place each twin in his or her own crib or bassinet. For parents who prefer co-bedding, the AAP urges that adequate space be allowed for each twin and that babies always be placed on their backs. Having twins sleep head to head was also suggested in the interest of good physical outcomes. 


\section{Career Choice}

A Stanford University alumni magazine article describing identical twins, Christopher and Benjamin Yeh, complements my last News Views and Comments essay in Twin Research and Human Genetics, on twins working together (Segal, 2018). Chris and Ben did not purposely pick the same career paths, but their interests and talents led these computer science majors toward bioengineering (Patton, 2018). Bioengineers apply engineering concepts and methods to issues and problems in medicine and biology. Examples of bioengineering activities include the design and production of artificial limbs and body organs (American Heritage Science Dictionary, 2011).

As Stanford undergraduate students, the twins immersed themselves in the sciences, studied abroad in Madrid and served as residential staff members in freshman dormitories. Twinship played a key role in their college applications, as it did for Adam and Todd Stone; see above. In his personal statement, Ben wrote about being an identical twin because of its significance for his identity. He elaborated by saying that text messages and telephone calls from his brother take priority over those from anyone else. Ben also admitted that he had relatively few friends while growing up, probably because he wanted companions to be just like his brother, so he set the bar too high.

The Yeh twins are continuing their educational journey together. Their immediate plan is for each to earn a master's degree in computer science and a doctoral degree after that.

\section{References}

American Heritage Science Dictionary. (2011). Bioengineering. Retrieved from https://www.dictionary.com/browse/bioengineering

Berk, L. E. (2013). Child development (9th ed.). Boston, MA: Pearson Education.

Bruni, F. (2018, September 18). The amputee who showed everyone. New York Times, p. A19.

Collins English Dictionary. (2018). Definition of 'nasion'. Retrieved from https://www.collinsdictionary.com/us/dictionary/english/nasion

Diamond, M. (2013). Transsexuality among twins: Identity concordance, transition, rearing and orientation. International Journal of Transgenderism, 14, $24-38$.

Fearon, J. A. (2010). Radiologic examination of the craniofacial skeleton. In J. Weinzweig (Ed.), Plastic surgery secrets plus (2nd ed., pp. 282-285). Philadelphia, PA: Elsevier Mosby.

Gbyl, K., \& Jorgensen, M. B. (2018). A case of Capgras syndrome and folie à deux in monozygotic twins. Neurocase, 24, 175-179.

Greengross, G., \& Martin, R. A. (2018). Health among humorists: Susceptibility to contagious diseases among improvisational artists. International Journal of Humor Research, 31, 491.

Greengross, G., Martin, R. A., \& Miller, G. F. (2012a). Personality traits, intelligence, humor styles, and humor production ability of professional stand-up comedians compared to college students. Psychology of Aesthetics, Creativity and the Arts, 6, 74-82.

Greengross, G., Martin, R. A., \& Miller, G. F. (2012b). Childhood experiences of professional comedians: Peer and parent relationships and humor use. Humor, 25, 491-505.
Greengross, G., \& Miller, G. F. (2009). The Big Five personality traits of professional comedians compared to amateur comedians, comedy writers, and college students. Personality and Individual Differences, 47, 79-83.

Hogeven, C. (2018). Should twins share a crib? An expert explains how to have multiples sleep safely. Romper. Retrieved from https://www.romper.com/p/ should-twins-share-a-crib-expert-explains-how-to-have-multiples-sleepsafely-11890440

Huppertz, C., Bartels, M., Van Beijsterveldt, C. E., Boomsma, D. I., Hudziak, J. J., \& De Geus, E. J. (2012). The impact of shared environmental factors on exercise behavior from age 7 to 12. Medicine and Science in Sports and Exercise, 44, 2025-2032.

Michel, A., Mormont, C., \& Legros, J. J. (2001). A psycho-endocrinological overview of transsexualism. European Journal of Endocrinology, 145, 365-376.

National Institutes of Health. (2018). What is noninvasive prenatal testing (NIPT) and what disorders can it screen for? Genetics Home Reference. Retrieved from https://ghr.nlm.nih.gov/primer/testing/nipt

Nichols, R. C., \& Bilbro, W. C., Jr. (1966). The diagnosis of twin zygosity. Human Heredity, 16, 265-275.

Patton, J. (2018). The Yeh-Yeh brotherhood. Stanford Magazine, September $18-19$.

Race, R. R., \& Sanger, R. (1975). Blood groups in man. Oxford, UK: Blackwell Scientific Publications.

Rach, J. (2018, October 23). Identical twins, 23, who were born female are now brothers after BOTH coming out as transgender — and they're going through the transition process together. Daily Mail. Retrieved from https://www.dailymail.co.uk?femail/article-6306369/Identical-twins-borngirls-brothers-transitioning-came-trasgender.html

Schermer, J. A., Martin, R. A., Vernon, P. A., Martin, N. G., Conde, L. C., Statham, D., \& Lynskey, M. T. (2017). Lonely people tend to make fun of themselves: A behavior genetic analysis of humor styles and loneliness. Personality and Individual Differences, 117, 71-73.

Segal, N. L. (2012). Born together - reared apart: The landmark Minnesota twin study. Cambridge, MA: Harvard University Press.

Segal, N. L. (2018). Twins working together: Collaboration or contest (News, Views \& Comments). Twin Research and Human Genetics, 21, 563-569.

Segal, N. L., McGuire, S. A., Havlena, J., Gill, P., \& Hershberger, S. L. (2007). Intellectual similarity of virtual twin pairs: Developmental trends. Personality and Individual Differences, 42, 1209-1219.

Stubbe, J. H., Boomsma, D. I., \& de Geus, J. C. N. (2005). Sports participation during adolescence: A shift from environmental to genetic factors. Medicine and Science in Sports and Exercise, 37, 563-570.

Subramaniam, P., Babu, K. G., \& Vardhana, B. (2018). Assessment of dental caries and oral hygiene status among twins. Journal of Forensic Science and Medicine, 4, 18-22.

Takahashi, M., Hosomichi, K., Yamaguchi, T., Nagahama, R., Yoshida, H., Marazita, M. L., ... Tajima, A. (2018). Exploration of genetic factors determining cleft side in a pair of monozygotic twins with mirror-image cleft lip and palate using whole-genome sequencing and comparison of craniofacial morphology. Archives of Oral Biology, 96, 33-38.

Takeda, E., Suzumori, N., Kumagai, K., Inuzuka, S., Oseto, K., Ohigashi, Y., ... Sugiura-Ogasawara, M. (2018). Performance and outcomes of noninvasive prenatal testing for twin pregnancies in Japan. Journal of Obstetrics and Gynaecology Research, 44, 1909-1914.

Veselka, L., Schermer, J. A., Martin, R. A., \& Vernon, P. A. (2010). Laughter and resiliency: A behavioral genetic study of humor styles and mental toughness. Twin Research and Human Genetics, 13, 442-449.

Wilson, R. S. (1983). The Louisville Twin Study: Developmental synchronies in behavior. Child Development, 54, 298-316. 